\title{
Effect of Alkali Metal Ions on Alkaline Ethanolysis of 2-Pyridyl and 4-Pyridyl Benzoates in Anhydrous Ethanol
}

\author{
Jae-In Lee, ${ }^{\dagger}$ Ji-Sun Kang, ${ }^{\dagger}$ Song-I Kim, and Ik-Hwan Um*

\begin{abstract}
Department of Chemistry and Nano Science, Ewha Womans University, Seoul 120-750, Korea. E-mail: ihum@ewha.ac.kr ${ }^{\dagger}$ Department of Chemistry and Plant Resources Research Institute, Duksung Women's University, Seoul 132-714, Korea Received August 16, 2010, Accepted August 30, 2010
\end{abstract}

\begin{abstract}
Pseudo-first-order rate constants $\left(k_{\mathrm{obsd}}\right)$ have been measured for nucleophilic substitution reactions of 2-pyridyl benzoate 5 with alkali metal ethoxides (EtOM, M $=\mathrm{Li}, \mathrm{Na}, \mathrm{K})$ in anhydrous ethanol. The plots of $k_{\text {obsd }} v s$. [EtOM]。 are curved upwardly but linear in the excess presence of 18-crown-6-ether (18C6) with significant decreased $k_{\text {obsd }}$ values in the reaction with EtOK. The $k_{\text {obsd }}$ value for the reaction of $\mathbf{5}$ with a given EtONa concentration decreases steeply upon addition of 15 -crown-5-ether $(15 \mathrm{C} 5)$ to the reaction medium up to $c a$. [15C5]/[EtONa $]_{\mathrm{o}}=1$, and remains nearly constant thereafter, indicating that $\mathrm{M}^{+}$ions catalyze the reaction in the absence of the complexing agents. Dissection $k_{\mathrm{obsd}}$ into $k_{\mathrm{EtO}}$ and $k_{\mathrm{EtOM}}$, i.e., the second-order rate constants for the reaction with the dissociated $\mathrm{EtO}^{-}$and the ion-paired EtOM, respectively has revealed that ion-paired EtOM is 3.2 - 4.6 times more reactive than dissociated $\mathrm{EtO}^{-}$. It has been concluded that $\mathrm{M}^{+}$ions increase the electrophilicity of the reaction center through a 6-membered cyclic transition state. This idea has been examined from the corresponding reactions of 4-pyridyl benzoate $\mathbf{6}$, which cannot form such a 6-membered cyclic transition state.
\end{abstract}

Key Words: Ethanolysis, Metal ion catalysis, Electrophilicity, Nucleofugality, Transition state

\section{Introduction}

The effect of metal ions on rates of nucleophilic substitution reactions of esters has been intensively investigated due to the importance in biological processes as well as synthetic interest. ${ }^{1-13}$ Alkali metal ions (e.g., $\mathrm{M}^{+}=\mathrm{Li}^{+}, \mathrm{Na}^{+}, \mathrm{K}^{+}$) have often been reported to catalyze acyl-group transfer reactions as a Lewis acid catalyst although they exert lower catalytic effects than multivalent metal ions. ${ }^{6-13}$ The first systematic study of $\mathrm{M}^{+}$ ion effect was performed by Buncel et al. in alkaline ethanolysis of 4-nitrophenyl diphenylphosphinate 1 with alkali metal ethoxides (EtOM, M $=\mathrm{Li}, \mathrm{Na}, \mathrm{K}){ }^{6}{ }^{6}$ They found that $\mathrm{M}^{+}$ions catalyze the reaction and the catalytic effect increases as the size of $\mathrm{M}^{+}$ ions decreases, i.e., $\mathrm{K}^{+}<\mathrm{Na}^{+}<\mathrm{Li}^{+}$. A similar result has been reported for the reactions of paraoxon 2a with EtOM in anhydrous ethanol. ${ }^{9}$ However, a contrasting result has been found for the corresponding reaction of parathion $\mathbf{2} \mathbf{b}$, a sulfur analogue of $\mathbf{2 a}$, i.e., $\mathrm{K}^{+}$and $\mathrm{Na}^{+}$catalyze the reaction while $\mathrm{Li}^{+}$behaves as an inhibit, indicating that the nature of the electrophilic center (e.g., $\mathrm{P}=\mathrm{O}$ vs. $\mathrm{P}=\mathrm{S}$ ) governs the role of $\mathrm{M}^{+}$ions. ${ }^{9}$

$\begin{array}{ccc}\text { O } & \text { O } & \text { S } \\ \mathrm{Ph} \text { \#-OAr } & \text { RO-P }- \text { OAr } & \text { RO-P-OAr } \\ \text { Ph } & \text { OR } & \text { OR } \\ 1 & 2 a & 2 b\end{array}$

The effect of $\mathrm{M}^{+}$ions on reactions of carboxylic esters with EtOM has also been investigated. ${ }^{6 a, 10} \mathrm{M}^{+}$ions have been reported to catalyze the reaction of 4-nitrophenyl benzoate $\mathbf{3}$ with EtOM in anhydrous ethanol in the order $\mathrm{K}^{+}>\mathrm{Na}^{+}>\mathrm{Li}^{+}$, although the catalytic effect is small. ${ }^{6 a}$ Significantly enhanced catalytic effect has recently been found for the corresponding reaction of 4-nitrophenyl picolinate 4 with a catalytic effect order $\mathrm{Na}^{+}>$ $\mathrm{K}^{+}>\mathrm{Li}^{+}$, implying that the effect of $\mathrm{M}^{+}$ions is also influenced by the environment of the reaction site. ${ }^{10 a}$
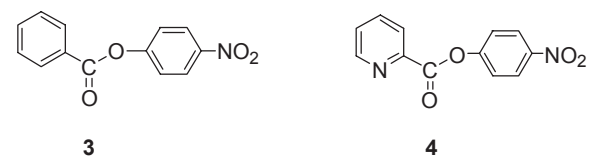

The large catalytic effect found for the reactions of $\mathbf{4}$ has been attributed to increase in the electrophilicity of the carbonyl carbon through 5-membered cyclic transition state I. ${ }^{10 \mathrm{a}} \mathrm{M}^{+}$ions would also catalyze the reactions of 4 by increasing the nucleofugality of the leaving group through 4-membered cyclic transition state II. However, the contribution of I to the catalytic effect has been suggested to be insignificant since the leavinggroup departure would occur after the rate-determining step (RDS).
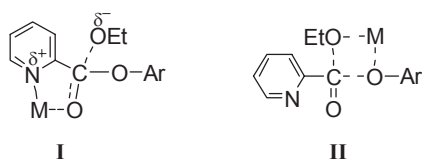

We have extended our study to reactions of 2-pyridyl benzoate 5 and 4-pyridyl benzoate $\mathbf{6}$ with EtOM in anhydrous ethanol to get further information on $\mathrm{M}^{+}$ion effect (Scheme 1). Esters possessing a 2-pyridyl moiety (e.g., 5) have often been reported to be an excellent acylating agent in reactions with Grignard reagents as well as in reactions with cupric bromide or lithium

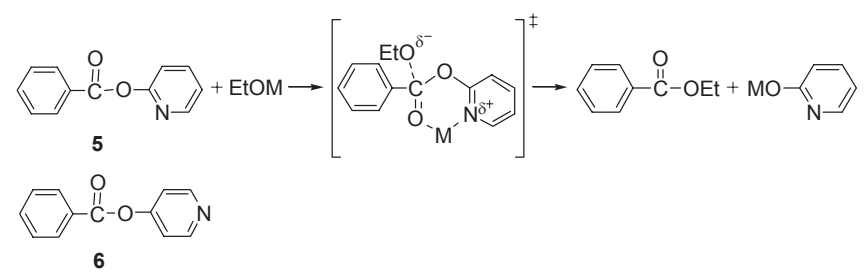

Scheme 1 
dialkylcuprate. ${ }^{14,15}$ We wish to report that $\mathrm{M}^{+}$ions catalyze the reaction of $\mathbf{5}$ by increasing the electrophilcity of the reaction center through a 6-membered cyclic transition state with an order of catalytic effect $\mathrm{Na}^{+}>\mathrm{Li}^{+}>\mathrm{K}^{+}$.

\section{Results and Discussion}

The kinetic study was performed spectrophotometrically under pseudo-first-order conditions with a large excess of EtOM. All reactions in the current study obeyed pseudo-first-order kinetics. Pseudo-first-order rate constants $\left(k_{\text {obsd }}\right)$ were obtained from the slope of linear plots of $\ln \left(A_{\infty}-A_{\mathrm{t}}\right) v s$. $t$. The correlation coefficients of the linear plots are usually higher than 0.9995 . From replicate runs, the uncertainty in the $k_{\text {obsd }}$ values is estimated to be less than $\pm 3 \%$. The $k_{\text {obsd }}$ values and detailed kinetic conditions for the reactions of $\mathbf{5}$ and $\mathbf{6}$ with EtOM are summarized in Tables S1 and S2, respectively in the Supporting Information.

Effect of $\mathbf{M}^{+}$ions on reactivity of EtOM. As shown in Figure 1, the plots of $k_{\text {obsd }} v s$. [EtOM] for the reactions of $\mathbf{5}$ with EtOM exhibit upward curvature as the concentration of EtOM increases. The upward curvature is most significant for the reaction with EtOLi. However, the plot for the reaction of 5 with EtOK in the presence of a complexing agent 18-crown6-ether (18C6) is linear with significantly decreased $k_{\text {obsd }}$ values. Thus, one can suggest that $\mathrm{M}^{+}$ions catalyze the reactions of $\mathbf{5}$ but the catalytic effect disappears in the presence of the complexing agent.

To provide further evidence for $\mathrm{M}^{+}$ion catalysis, the reaction of 5 with EtONa has been performed at a given [EtONa $]_{0}$ with varying the concentration of 15-crown-5-ether (15C5), a complexing agent for $\mathrm{Na}^{+}$ion. The kinetic results are illustrated in Figure 2. One can see that the $k_{\text {obsd }}$ value at a given [EtONa $]_{\mathrm{o}}$ decreases steeply as the $[15 \mathrm{C} 5] /[\mathrm{EtONa}]_{\mathrm{o}}$ ratio increases up to ca. 1.0 and remains nearly constant thereafter. This result indicates that $15 \mathrm{C} 5$ complexes $\mathrm{Na}^{+}$ion almost completely when

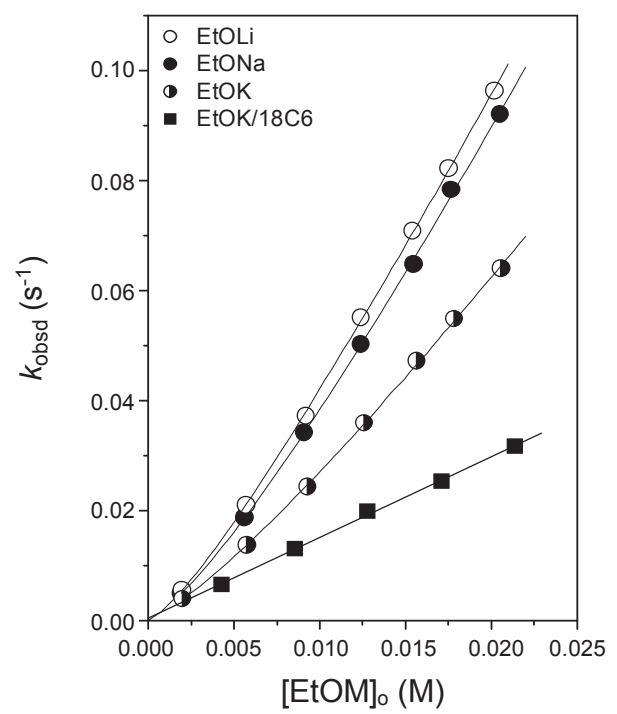

Figure 1. Plots of $k_{\mathrm{obsd}} v s$. [EtOM] for reactions of 2-pyridyl benzoate 5 with $\operatorname{EtOLi}(\circ), \operatorname{EtONa}(\bullet), \operatorname{EtOK}(\mathbf{\bullet})$, and with $\mathrm{EtOK}$ in the presence of $18 \mathrm{C} 6(\boldsymbol{\square})$ in anhydrous EtOH at $25.0 \pm 0.1^{\circ} \mathrm{C}$. $[18 \mathrm{C} 6] /[\mathrm{EtOK}]_{0}=5.0$.
$[15 \mathrm{C} 5] /[\mathrm{EtONa}]_{\mathrm{o}}=1.0$, and the crowned $\mathrm{Na}^{+}$ion does not catalyze the reaction. Thus, one can conclude that $\mathrm{M}^{+}$ions catalyze the reactions of $\mathbf{5}$ with EtOM in the absence of complexing agents $18 \mathrm{C} 6$ or $15 \mathrm{C} 5$.

Dissection of $\boldsymbol{k}_{\text {obsd }}$ into $\boldsymbol{k}_{\mathrm{EtOM}}$ and $\boldsymbol{k}_{\mathrm{EtO}}$. To quantify the catalytic effect shown by $\mathrm{M}^{+}$ions, the $k_{\text {obsd }}$ values have been dissected into $k_{\mathrm{EtO}}$ and $k_{\mathrm{EtOM}}$, i.e., the second-order rate constants for the reaction with dissociated $\mathrm{EtO}^{-}$and ion-paired EtOM, respectively. It has been reported that alkali metal ethoxides exist as dimers or other aggregates in a high concentration region (e.g., $\left.[\mathrm{EtOM}]_{\mathrm{o}}>0.1 \mathrm{M}\right) .{ }^{16}$ However, EtOM has been suggested to exist as dissociated and ion-paired species in concentration below $0.1 \mathrm{M}^{16}$ Since the current reactions were performed in a low concentration region (e.g., $[\mathrm{EtOM}]_{\mathrm{o}}<0.025 \mathrm{M}$ ), one might expect that EtOM exists as dissociated $\mathrm{EtO}^{-}$and ion-paired EtOM.

It is apparent that both dissociated $\mathrm{EtO}^{-}$and ion-paired EtOM could react with substrate $\mathbf{5}$ as shown in Scheme 2. Thus, the rate equation can be expressed as eq (1). Since all reactions were performed under pseudo-first-order conditions, $k_{\text {obsd }}$ can be expressed as eq (2). Note that the dissociation constant $K_{\mathrm{d}}=$ $\left[\mathrm{EtO}^{-}\right]_{\mathrm{eq}}\left[\mathrm{M}^{+}\right]_{\mathrm{eq}} /[\mathrm{EtOM}]_{\mathrm{eq}}$, and $\left[\mathrm{EtO}^{-}\right]_{\mathrm{eq}}=\left[\mathrm{M}^{+}\right]_{\mathrm{eq}}$ at the equilibrium, eq (2) becomes eq (3). Besides, the concentration of $\mathrm{EtO}^{-}$and $\mathrm{EtOM}$ at equilibrium can be calculated from the reported $K_{\mathrm{d}}$ and the initial [EtOM] $]_{\mathrm{o}}$ as shown in eqs (4) and (5). Accordingly, one might expect that the plots of $k_{\mathrm{obsd}} /\left[\mathrm{EtO}^{-}\right]_{\mathrm{eq}}$ $v s$. [EtO $]_{\mathrm{eq}}$ are linear and pass through a common intercept regardless of the nature of $\mathrm{M}^{+}$ions. This is because the intercept

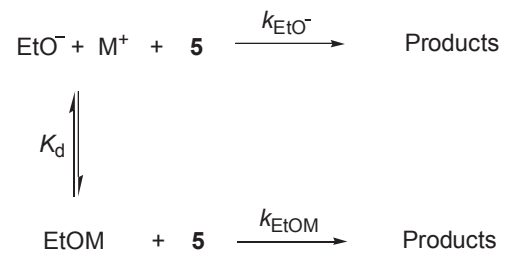

Scheme 2

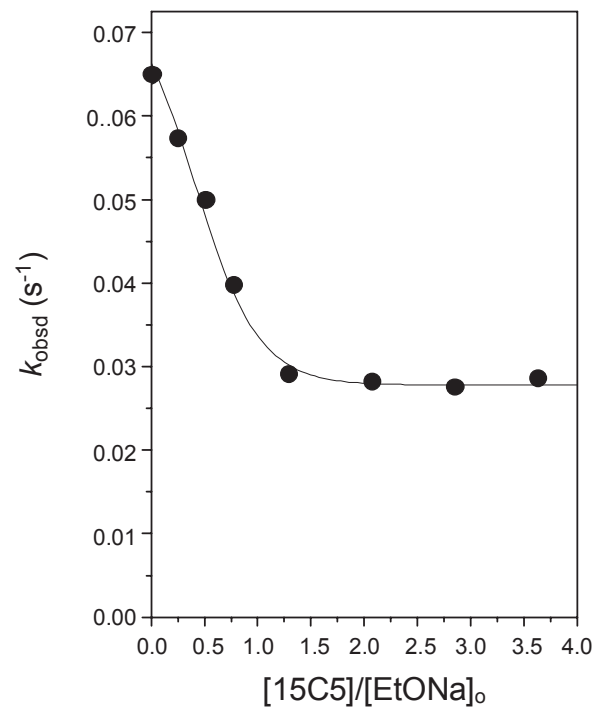

Figure 2. Plot showing the effect of added $15 \mathrm{C} 5$ on $k_{\mathrm{obsd}}$ for the reaction of 2-pyridyl benzoate 5 with EtONa in anhydrous EtOH at $25.0 \pm$ $0.1{ }^{\circ} \mathrm{C} .[\mathrm{EtONa}]_{\mathrm{o}}=15.5 \mathrm{mM}$. 
represents $k_{\mathrm{EtO}^{-}}$, which is independent of $\mathrm{M}^{+}$ions as shown in eq (3).

$$
\begin{aligned}
& \text { Rate }=k_{\mathrm{EtO}^{-}}\left[\mathrm{EtO}^{-}\right]_{\mathrm{eq}}[5]+k_{\mathrm{EtOM}}[\mathrm{EtOM}]_{\mathrm{eq}}[5] \\
& k_{\mathrm{obsd}}=k_{\mathrm{EtO}^{-}}\left[\mathrm{EtO}^{-}\right]_{\mathrm{eq}}+k_{\mathrm{EtOM}}[\mathrm{EtOM}]_{\mathrm{eq}} \\
& k_{\mathrm{obsd}} /\left[\mathrm{EtO}^{-}\right]_{\mathrm{eq}}=k_{\mathrm{EtO}^{-}}+k_{\mathrm{EtOM}}\left[\mathrm{EtO}^{-}\right]_{\mathrm{eq}} / K_{\mathrm{d}} \\
& {[\mathrm{EtOM}]_{\mathrm{o}}=\left[\mathrm{EtO}^{-}\right]_{\mathrm{eq}}+\left[\mathrm{EtOM}_{\mathrm{eq}}\right.} \\
& {\left[\mathrm{EtO}^{-}\right]_{\mathrm{eq}}=\left[-K_{\mathrm{d}}+\left(K_{\mathrm{d}}^{2}+4 K_{\mathrm{d}}[\mathrm{EtOM}]_{\mathrm{o}}\right)^{1 / 2}\right] / 2}
\end{aligned}
$$

To examine the above argument, plots of $k_{\text {obsd }} /\left[\mathrm{EtO}^{-}\right]_{\text {eq }} v s$. $\left[\mathrm{EtO}^{-}\right]_{\mathrm{eq}}$ have been constructed. As shown in Figure 3, the plots exhibit excellent linear correlation with nearly an identical intercept, indicating that the mechanism proposed in Scheme 2 and eqs (1)-(3) are correct. Accordingly, $k_{\mathrm{EtOM}} / K_{\mathrm{d}}$ and $k_{\mathrm{EtO}}-$ have been determined from the slope and intercept of the linear plots, respectively. Since the $K_{\mathrm{d}}$ values were reported to be $4.72 \times 10^{-3}$, $9.80 \times 10^{-3}$, and $11.1 \times 10^{-3} \mathrm{M}$ for EtOLi, EtONa, and EtOK, respectively, ${ }^{17}$ the $k_{\text {EtOM }}$ values could be calculated from the $k_{\mathrm{EtOM}} / K_{\mathrm{d}}$ values. The $k_{\mathrm{EtO}}$ and $k_{\mathrm{EtOM}}$ values calculated in this way are summarized in Table 1.

As shown in Table 1, the $k_{\mathrm{EtO}}$ values determined from the intercept of the linear plots range from 1.45 to $1.75 \mathrm{M}^{-1} \mathrm{~s}^{-1}$, in-

Table 1. Summary of second-order rate constants from ion-pairing treatment of kinetic data for reactions of 2-pyridyl benzoate 5 with EtOM in anhydrous EtOH at 25.0 $\pm 0.1{ }^{\circ} \mathrm{C}$.

\begin{tabular}{ccc}
\hline EtOM & $k_{\mathrm{EtO}^{-}}\left(\mathrm{M}^{-1} \mathrm{~s}^{-1}\right)$ & $k_{\mathrm{EtOM}}\left(\mathrm{M}^{-1} \mathrm{~s}^{-1}\right)$ \\
\hline EtOLi & 1.46 & 6.48 \\
EtONa & 1.74 & 7.19 \\
EtOK & 1.45 & 4.90 \\
EtOK/18C6 & 1.46 & - \\
\hline
\end{tabular}

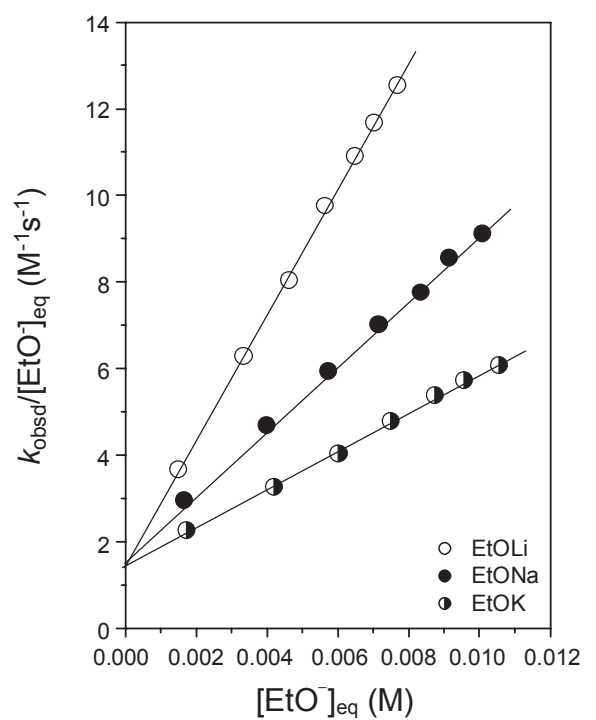

Figure 3. Plots illustrating dissection of $k_{\mathrm{obsd}}$ into $k_{\mathrm{EtO}}$ and $k_{\mathrm{EtOM}}$ reactions of 2-pyridyl benzoate $\mathbf{5}$ with EtOM in anhydrous EtOM at $25.0 \pm 0.1{ }^{\circ} \mathrm{C}$. dicating that some uncertainties are involved in the $k_{\mathrm{EtO}}-$ values. A more accurate $k_{\mathrm{EtO}}$ value can be measured directly from the slope of the linear plot for the reaction of $\mathbf{5}$ with EtOK in the excess presence of $18 \mathrm{C} 6$ (e.g., $[18 \mathrm{C} 6] /[\mathrm{EtOK}]=5.0$ ) as shown in Figure 1. This is because $\mathrm{K}^{+}$ion would be complexed completely by $18 \mathrm{C} 6$ and the crowned $\mathrm{K}^{+}$ion does not catalyze the reaction (see also Figure 2). The $k_{\mathrm{EtO}^{-}}$value determined in this way is $1.46 \mathrm{M}^{-1} \mathrm{~s}^{-1}$, which is practically identical to the average $k_{\text {EtO- }}$ values determined from the intercepts of the linear plots shown in Figure 3.

One can see from Table 1 that the ion-paired species are more reactive than dissociated $\mathrm{EtO}^{-}$. This is consistent with the preceding argument that $\mathrm{M}^{+}$ions behaves as a catalyst in the reactions of 5. Interestingly, the reactivity increases in the order $\mathrm{EtO}^{-}<\mathrm{EtOK}<\mathrm{EtOLi}<\mathrm{EtONa}$, indicating that $\mathrm{Na}^{+}$ion exhibits the highest catalytic effect.

Origin of $\mathbf{M}^{+}$ion catalysis. Alkaline hydrolysis of carboxylic esters has generally been suggested to proceed through a stepwise mechanism with formation of an intermediate being the RDS. ${ }^{18,19}$ Thus, one might expect that the current reaction also proceed through a stepwise mechanism. If the reaction proceeds through a stepwise mechanism, departure of the leaving group from the intermediate would occur after the RDS. This is because $\mathrm{EtO}^{-}$is more basic and a poorer leaving group than 2-pyridyloxide.

$\mathrm{M}^{+}$ion might catalyze the reaction of 5 either by increasing the nucleofugality of the leaving group or by increasing the electrophilicity of the reaction center as illustrated in 4- or 6-membered complexes III or IV, respectively. However, the effect of enhanced nucleofugality would be negligible for reactions in which the leaving-group departure occurs after the rate-determining step (RDS). Thus, one might suggest that the large catalytic effect shown by $\mathrm{M}^{+}$ions would not be due to increased nucleofugality but due to increased the electrophilicity of the electrophilic center through a 6-membered cyclic transition state IV.

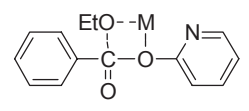

III

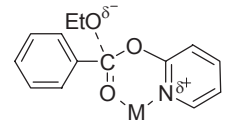

IV
As mentioned above, $\mathrm{Na}^{+}$ion exhibits the highest catalytic effect. Such high $\mathrm{Na}^{+}$ion selectivity has recently been reported for alkaline ethanolysis of 4-nitrophenyl picolinate 4 and 5-nitro8-quinolyl benzoate. ${ }^{10 \mathrm{a}}$ A common feature of these compounds including $\mathbf{5}$ is possession of a nitrogen atom which can participate in formation of a 5- or 6-membered cyclic complex in the transition state (e.g., I and IV). Thus, one can propose that $\mathrm{Na}^{+}$ion stabilizes transition state IV most strongly among the alkali metal ions employed in this study.

To examine the above idea that $\mathrm{M}^{+}$ion catalyzes the current reaction by stabilizing the transition state through complex IV, reactions of 4-pyridyl benzoate 6 with EtOM have been performed in anhydrous ethanol. Since the reactions of $\mathbf{6}$ cannot form a 6-membered cyclic transition state (e.g., IV), the effect of $\mathrm{M}^{+}$ions on reactivity of $\mathbf{6}$ would be quite different from that 


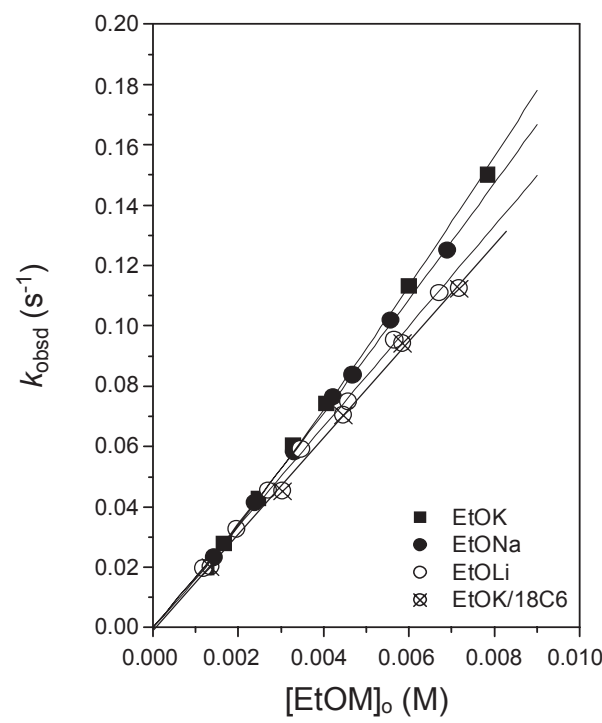

Figure 4. Plots of $k_{\mathrm{obsd}} v s$. [EtOM] for reactions of 4-pyridyl benzoate $\mathbf{6}$ with $\operatorname{EtOK}(\boldsymbol{\bullet}), \operatorname{EtONa}(\bullet), \operatorname{EtOLi}(\circ)$ and EtOK in the presence of $18 \mathrm{C} 6(\otimes)$ in anhydrous EtOH at $25.0 \pm 0.1{ }^{\circ} \mathrm{C}$.

found for the corresponding reactions of $\mathbf{5}$. In fact, as shown in Figure 4 , plots of $k_{\mathrm{obsd}} v s$. [EtOM] $]_{\mathrm{o}}$ for the reactions of $\mathbf{6}$ with EtOK and EtONa are curved upwardly while the corresponding plots for the reactions with EtOLi and EtOK/18C6 are linear. Besides, the curvature is not significant, indicating that the effect of $\mathrm{M}^{+}$ions on reactivity of $\mathbf{6}$ is insignificant. It is also noted that the reactivity of EtOM decreases in the order EtOK > $\mathrm{EtONa}>\mathrm{EtOLi} \geq \mathrm{EtOK} / 18 \mathrm{C} 6$, which is also contrasting to the reactivity order found for the corresponding reactions of $\mathbf{5}$. Thus, one can conclude that the difference in $\mathrm{M}^{+}$ion effects found in this study is mainly due to the difference in their transition state structures, since a 6-membered cyclic transition state IV is possible for the reactions of 5 but impossible for the reactions of $\mathbf{6}$.

\section{Conclusions}

The current study has allowed us to conclude the following: (1) The plots of $k_{\mathrm{obsd}} v s$. [EtOM $]_{\mathrm{o}}$ for the reactions of $\mathbf{5}$ exhibit upward curvature, indicating that $\mathrm{M}^{+}$ions catalyze the reaction. (2) The reactivity of EtOM toward $\mathbf{5}$ decreases significantly in the presence of the complexing agents such as $15 \mathrm{C} 5$ and $18 \mathrm{C} 6$, implying that the $\mathrm{M}^{+}$ion catalysis disappears in the presence of the complexing agents. (3) Dissection of $k_{\mathrm{obsd}}$ into $k_{\mathrm{EtO}}-$ and $k_{\text {Etom }}$ has revealed that ion-paired EtOM is $3.2-4.6$ fold more reactive than the dissociated $\mathrm{EtO}^{-}$toward 5. (4) $\mathrm{M}^{+}$ion catalysis is insignificant for the reactions of 6. (5) The Enhanced electrophilicity through 6-membered cyclic transition state IV is responsible for the $\mathrm{M}^{+}$ion catalysis.

\section{Experimental Section}

Materials. Compounds 5 and $\mathbf{6}$ were readily prepared from the reaction of benzoyl chloride with 2-hydroxypyridine and 4-hydroxypyridine, respectively in anhydrous ether. The crude compounds 5 and $\mathbf{6}$ were purified by recrystallization. Their purity was confirmed by melting points and ${ }^{1} \mathrm{H}$ NMR spectra.
The solutions of EtOM were prepared by dissolving the respective alkali metal in anhydrous ethanol under $\mathrm{N}_{2}$ and stored in the refrigerator. The concentrations of EtOM stock solutions were measured by titration with mono potassium phthalate. Crown ethers (18C6 and 15C5) were recrystallized from acetonitrile and dried under vacuum. The anhydrous ethanol was further dried over magnesium and distilled under $\mathrm{N}_{2}$ just before use.

Kinetics. Kinetic study was performed using a UV-vis spectrophotometer equipped with a constant-temperature circulating bath. The reactions were followed by monitoring the appearance of the leaving 2-pyridyloxide at $298 \mathrm{~nm}$ (or 4-pyridyloxide at $270 \mathrm{~nm}$ ). Reactions were followed generally for $9-10$ half-lives and $k_{\text {obsd }}$ values were calculated using the equation, $\ln \left(A_{\infty}-\right.$ $\left.A_{t}\right)$ vs. $t$.

Product analysis. 2-Pyridyloxide (or 4-pyridyloxide) was liberated quantitatively and identified as one of the reaction products by comparison of the UV-vis spectra after completion of the reactions with those of the authentic samples under the reaction conditions.

Acknowledgments. This research was supported by Basic Science Research Program through the National Research Foundation of Korea (NRF) funded by the Ministry of Education, Science and Technology (2009-0075488). J. I. Lee also thanks for the financial support from Priority Research Centers Program through the National Research Foundation of Korea (NRF) funded by the Ministry of Education, Science and Technology (2009-0094018). S. I. Kim is also grateful for the BK 21 Scholarship.

Supporting Information. Tables S1 and S2 for the kinetic conditions and results for the reactions of $\mathbf{5}$ and $\mathbf{6}$ with EtOM, respectively.

\section{References}

1. (a) Fersht, A. Enzyme Structure and Mechanism; W. H. Freeman and company: New York, 1985. (b) Stryer, L. Biochemistry; W. H. Freeman and company: New York, 1988. (c) Da Silva, J. J. R. F.; Williams, R. J. P. The Biological Chemistry of the Elements; Clarendon Press: Oxford, 1991. (d) Anslyn, E. V.; Dougherty, D. E. Modern Physical Organic Chemistry; University Science Books: Sausalito, USA, 2006; pp 500-502. (e) Carroll, F. A. Perspectives on Structure and Mechanism in Organic Chemistry; Brooks/Cole: New York, USA, 1998; p 445. (f) Page, M. I.; Williams, A. Organic \& Bioorganic Mechanisms; Longman: Singapore, 1997; pp 179183.

2. (a) Brown, R. S.; Neverov, A. A. Adv. Phys. Org. Chem. 2007, 42, 271-331. (b) Davies, A. G. Perkin 1 2000, 1997-2010. (c) Williams, N. H.; Takasaki, B.; Wall, M.; Chin, J. Acc. Chem. Res. 1999, 32, 485-493. (d) Suh, J. Acc. Chem. Res. 1992, 25, 273-279. (e) Thatcher, G. R. J.; Kluger, R. Adv. Phys. Org. Chem. 1989, 25, 99-265. (f) Breslow, R. Adv. Enzymol. 1986, 58, 1-60. (g) Chin, J. Acc. Chem. Res. 1991, 24, 145-152.

3. (a) Fife, T. H.; Chauffe, L. Bioorg. Chem. 2000, 28, 357-373. (b) Fife, T. H.; Bembi, R. J. Am. Chem. Soc. 1993, 115, 11358-11363. (c) Fife, T. H.; Pujari, M. P. J. Am. Chem. Soc. 1990, 112, 55515557.

4. (a) Suh, J.; Son, S. J.; Suh, M. P. Inorg. Chem. 1998, 37, 48724877. (b) Suh, J.; Kim, N.; Cho, H. S. Bioorg. Med. Chem. Lett. 1994, 4, 1889-1892. 
5. (a) Liu, C. T.; Neverov, A. A.; Maxwell, C. I.; Brown, R. S. J. Am. Chem. Soc. 2010, 132, 3561-3573. (b) Edwards, D. R.; Tsang, W. Y.; Neverov, A. A.; Brown, R. S. Org. Biomol. Chem. 2010, 84, 822-827. (c) Brown, R. S.; Lu, Z, L.; Liu, C. T.; Tsang, W. Y.; Edwards, D. R.; Neverov, A. A. J. Phys. Org. Chem. 2010, 23, 1-15. (d) Mohamed, M. F.; Neverov, A. A.; Brown, R. S. Inorg. Chem. 2009, 48, 11425-11433. (e) Gibson, G. T. T.; Mohamed, M. F.; Neverov, A. A.; Brown, R. S. Inorg. Chem. 2006, 45, 7891-7902. (f) Gibson, G. T. T.; Neverov, A. A.; Teng, A. C.-T.; Brown, R. S. Can. J. Chem. 2005, 83, 1268-1276.

6. (a) Pregel, M. J.; Dunn, E. J.; Nagelkerke, R.; Thatcher, G. R. J.; Buncel, E. Chem. Soc. Rev. 1995, 24, 449-455. (b) Dunn, E. J.; Buncel, E. Can. J. Chem. 1989, 67, 1440-1448. (c) Buncel, E.; Dunn, E. J.; Bannard, R. B.; Purdon, J. G. Chem. Commun. 1984, 162-163.

7. (a) Koo, I. S.; Ali, D.; Yang, K.; Park, Y.; Esbata, A.; van Loon, G. W.; Buncel, E. Can. J. Chem. 2009, 87, 433-439. (b) Buncel, E; Albright, K. G.; Onyido, I. Org. Biomol. Chem. 2005, 3, 14681475. (c) Buncel, E.; Albright, K. G.; Onyido, I. Org. Biomol. Chem. 2004, 2, 601-610. (d) Nagelkerke, R.; Thatcher, G. R. J.; Buncel, E. Org. Biomol. Chem. 2003, 1, 163-167.

8. (a) Buncel, E.; Nagelkerke, R.; Thatcher, G. R. J. Can. J. Chem. 2003, 81, 53-63. (b) Pregel, M. J.; Dunn, E. J.; Buncel, E. J. Am. Chem. Soc. 1991, 113, 3545-3550. (c) Pregel, M. J.; Buncel, E. J. Org. Chem. 1991, 56, 5583-5588.

9. (a) Um, I. H.; Shin, Y. H.; Lee, S. E.; Yang, K.; Buncel, E. J. Org. Chem. 2008, 73, 923-930. (b) Um, I. H.; Jeon, S. E.; Baek, M. H.; Park, H. R. Chem. Commun. 2003, 3016-3017.

10. (a) Hong, Y. J.; Kim, S. I.; Um, I. H. Bull. Korean Chem. Soc. 2010, 31, in press. (b) Seo, J. A.; Kim, S. I.; Hong, Y. J.; Um, I. H. Bull. Korean Chem. Soc. 2010, 31, 303-308. (c) Um, I. H.; Lee, S. E.; Park, J. E. Bull. Korean Chem. Soc. 2008, 29, 1295-1296. (d) Um,
I. H.; Lee, S. E.; Hong, Y. J.; Park, J. E. Bull. Korean Chem. Soc. 2008, 29, 117-121.

11. (a) Mentz, M.; Modro, A. M.; Modro, T. A. Can. J. Chem. 1994, 72, 1933-1936. (b) Mentz, M.; Modro, T. A. J. Chem. Soc. Perkin Trans. 2 1995, 2227-2229.

12. Albanese, D.; Landini, D.; Maia, A. J. Org. Chem. 2001, 66, 32493252.

13. Paola, G. T.; Idania, V. Z.; Olga, T.; Yatsimirsky, A. K. J. Org. Chem. 2006, 71, 9713-9722.

14. (a) Lee, J. I. Bull. Korean Chem. Soc. 2010, 31, 749-752. (b) Lee, J. I. Bull. Korean Chem. Soc. 2007, 28, 863-866. (c) Kim, S.; Lee, J. I. J. Org. Chem. 1984, 49, 1712-1716. (d) Kim, S.; Lee, J. I.; Ko, Y. K. Tetrahedron Lett. 1984, 25, pp 4943-4946. (e) Kim, S.; Lee, J. I. J. Org. Chem. 1983, 48, 2608-1716.

15. (a) Mukaiyama, T.; Araki, M.; Takei, H. J. Amer. Chem. Soc. 1973, 95, 4763-4765. (b) Araki, M.; Sakata, S.; Takei, H.; Mukaiyama, T. Bull. Chem. Soc. Jpn. 1974, 47, 1777-1780.

16. Pechanec, V.; Kocian, O.; Zavada, J. Collect. Czech. Chem. Commun. 1982, 47, 3405-3411.

17. Barthel, J.; Justice, J-C.; Wachter, R. Z. Phys. Chem. 1973, 84, 100-113.

18. (a) Jones, R. A. Y. Physical and Mechanistic Organic Chemistry; Cambridge: Norwich, 1984; pp 265-287. (b) Samuel, D.; Silver, B. L. Adv. Phys. Org. Chem. 1965, 87, 123-186. (c) Johnson, S. L. Adv. Phys. Org. Chem. 1967, 5, 237-330. (d) McClelland, R. A.; Santry, L. J. Acc. Chem. Res. 1983, 16, 394-399.

19. (a) Um, I. K.; Lee, J. Y.; Fujio, M.; Tsuno, Y. Org. Biomol. Chem. 2006, 4, 2979-2985. (b) Zhan, C. G.; Landry, D. W.; Ornstein, R. L. J. Am. Chem. Soc. 2000, 122, 1522-1530. (c) Hori, K.; Hashitani, Y.; Kaku, Y.; Ohkubo, K. Theochem. 1999, 461-462, 589-596. (d) Kirsch, J. F.; Clewell, W.; Simon, A. J. Org. Chem. 1968, 33, 127-132. 